\section{Thomas Lönngren}

In his attempts to streamline the European Medicines Agency,

Thomas Lönngren's style is one of evolution rather than revolution.

It's hard to imagine the commissioner of the US Food and Drug Administration (FDA) out of the spotlight. But being executive director of Europe's principal regulatory agency, the European Medicines Agency (EMA, formerly the EMEA), means that Thomas Lönngren often must work in the background to promote a consensus among European member states participating in the EMA.

Lönngren's patient and inclusive style contrasts sharply with that of his predecessor, Fernand Sauer, whom he succeeded as EMEA executive director in 1999. Previously, Lönngren was a director of operations for medicinal products at the Swedish Medical Products Agency (MPA) in Uppsala. He also held various other regulatory positions, including that of an assessor for new drugs and has experience in approving medical devices and herbal medicine.

His diplomatic qualities have proved very useful in negotiating the cultural minefields encountered in the EMA's dealings with 25 national regulatory agencies. He has "brought with him from Sweden a rather casual style," says Anita Finne-Grahnén, who occupies Lönngren's previous job at the MPA. His typically Scandinavian creative and flexible management style contrasts sharply with the more hierarchical style of Frenchman Sauer. Yet some see him as less of a visionary than Sauer because he is "more technical than political," having spent his entire career devoted to regulatory affairs.

Lönngren's goals for the EMA are nonetheless ambitious. With the number of drugs approved by EMA falling recently (from 48 in 2001 to only 36 in 2003), he aims to reverse the trend and hopes that the number of EMA approvals will not slip below that of the FDA, which gave the green light to 21 new molecular entities last year. And some of EMA's approvals may not come from new drugs. Mounting pressure on the EU governments to save on public health spending is driving efforts to encourage the market entry of generic products, including follow-on biologics.

To increase efficiencies at the EMA, Lönngren's task is to find ways of speeding up the bureaucratic European regulatory framework and implementing the new pharmaceutical legislation approved by the European Parliament in March this year. Regulatory approval in Europe is split between the scientific advice given by EMA and the final decision provided by the European Commission, which makes the process somewhat schizophrenic. Unfortunately, EU bureaucracy may have already claimed one casualty. In November last year, Sandoz's human growth hormone (Omnitrop), which would have been Europe's first follow-on biologic, failed to win approval-not because of any problem with safety or efficacy but because the drug's application was filed before the new legislation was in place and thus failed to fulfill all new legal requirements (Nat. Biotechnol. 22, 497, 2004).

Although he won't comment on the Sandoz case, Lönngren believes that the current setback to follow-on biologics in Europe is only temporary. "We are prepared," he says. "It is only a matter of time" before they make it to market. Indeed, legislation that was passed in June 2004 will allow generics companies to carry out development and clinical trials before the expiry of the patents of the original biologic products beginning in November 2005.

Another key goal for Lönngren will be to address the perception of the industry that there is a lack of transparency at his agency. He has already committed, for example, to make drug assessment reports available in a manner and form that is accessible to the general public. He has also produced a long-term strategy document-known rather derivatively as the '2010 Roadmap' - that promises, among other things, to increase the level of 'nonbinding' advice given to small and medium enterprises and to provide it at a much earlier stage than before.

Although the Roadmap is going in the right direction, many industry critics remain unconvinced. Companies feel a "much greater sense of prickliness" dealing with the EMA than with the FDA, according to Chris Webster, director of regulatory strategy and intelligence at Millennium Pharmaceuticals in Cambridge, Massachusetts. When industry representatives visit EMA, for example, they are given a distinctive red badge, which is seen by some as a warning sign.

Lönngren says, "It is only a matter of time" before biogenerics make it to market.

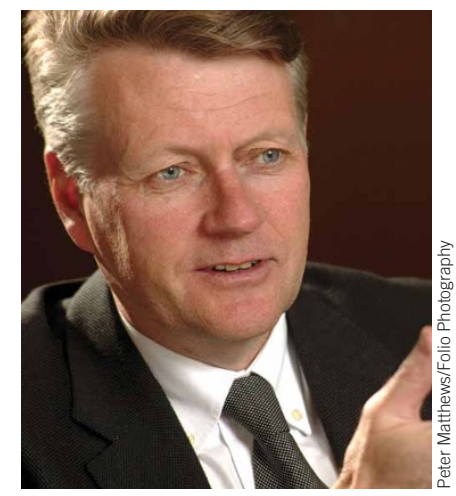

"Today, industry develops drugs in a black box and then, in general, delivers them into another black box at EMA," says Erik Tambuyzer, Genzyme Corporation's senior vice president of Corporate Affairs Europe in Brussels. What is needed is much more openness, he adds. "In the future, there should be some type of collaboration in both phases." But instead of getting industry's advice at an earlier stage in its working group or when drafting guidelines, the EMA has preferred to make a statement of independence from industry by getting some expertise from abroad. Last year, an agreement for "parallel scientific advice" was signed between the EMA and the FDA. Despite the reciprocal agreement with the FDA, "potentially, there could be a significant skill gap at the level of the reviewers," according to Webster. This could be a particular issue in emerging technology areas, such as cell therapies, tissue engineering and pharmacogenomics, where industry often has more expertise than agencies.

Whether it is getting industry involved in working groups or drafting guidelines, follow-on biologics or innovative drugs, clearly a more collaborative relationship is needed. Lönngren will need all his diplomacy and persistence to make this happen. And he may not have that long: his term expires in 2005.

Sabine Louët, Dublin 